\title{
Kinetics of Adsorption of Reactive Red 120 Using Bentonite Modified by CTAB and Study the Effect of Salts
}

\author{
Hasan Fadhil Al Rubai $\uparrow *$, Ahmed Khudhair Hassan*, Muntadhar Salih Sultan** \\ and Waleed Mohammed Abood*** \\ *Ministry of Science and Technology, Environment and Water Directorate, Baghdad, Iraq \\ ** Department of Chemistry, College of Science, University of Al-Mustansiriya, Baghdad, Iraq \\ ***Ministry of industry, Industrial Research and Development Authority, Chemical Research Center, Baghdad, Iraq \\ $\dagger$ Corresponding author: Hasan Fadhil Al Rubai; hasanfalrubai66@gmail.com
}

Nat. Env. \& Poll. Tech.

Website: www.neptjournal.com

Received: 07-12-2020

Revised: $24-02-2020$

Accepted: 28-03-2020

\section{Key Words:}

Adsorption

Decolorization

Modified bentonite

Reactive red 120

\begin{abstract}
Commercial bentonite was activated by aluminium hydroxide and then modified by cetyl trimethyl ammonium bromide (CTAB). The properties of modified bentonite were diagnosed using FTIR, X-ray diffraction and SEM. The adsorption of Reactive Red 120 (RR120) onto supported bentonite (B.A.CTAB) was investigated. The influence of various experimental parameters, such as temperature, initial concentration of dye, adsorbent dosages, initial $\mathrm{pH}$ and inorganic salts on RR120 removal was studied. The results showed that the optimum conditions for dye adsorption on modified bentonite are: temperature $=303 \mathrm{k}, \mathrm{pH}=3.5$, contact time $=10 \mathrm{~min}$, adsorbent dosage $=0.1 \mathrm{~g}$ and RR 120 concentration $96 \mathrm{mg} \cdot \mathrm{L}^{-1}$, it achieved a removal efficiency of $91 \%$. The pseudo-second-order version yields a higher fit to the experimental facts than the pseudo-first-order model. The consequences revealed that Langmuir version turned into extra appropriate to explain RR120 adsorption than the Freundlich model. Also, the thermodynamic function such as $\Delta \mathrm{G}^{\circ}, \Delta \mathrm{H}^{\circ}$ and $\Delta \mathrm{S}^{\circ}$ was evaluated. The consequences of various inorganic anions (which included $\mathrm{Cl}^{-}, \mathrm{SO}_{4}^{2-}, \mathrm{CO}_{3}^{2-}$, and so forth.) on the removal activity of RR 120 adsorption on modified bentonite was examined.
\end{abstract}

\section{INTRODUCTION}

The rapid development in the field of industry with the increasing discharge of industrial wastewater has become a major problem in the pollution of the environment (Zhang \& Qiu 2019). Azo dyes are commonly used in the textile industry. These dyes are highly poisonous and difficult to decompose and their presence in wastewater leads to high organic pollution content, deep colour and significant effluence on microorganisms (Qiu 2019). There are significant challenges to getting rid of this pollution to obtain high quality water. In recent years, many wastewater treatment technologies have evolved from textile industries including adsorption, advanced oxidation, electrochemical methods, coagulation, etc. (Suba \& Rathika 2016); but prefer the method of adsorption because it is a low cost, easy to operate and highly efficient in dealing with various organic and inorganic pollutants (Fan et al. 2015). Many of the adsorbent materials are economically or easy to access and have been verified in many research studies such as ferric hydroxide (Konicki et al. 2015), blast furnace slag (Zhang et al. 2013), palygorskite (Giustetto \& Wahyudi 2011), palm ash (Hameed et al. 2007), zeolite (Engin et al. 2008), and oxide tailings (Giri et al. 2011). Bentonite is clay, in particular, constituted by way of the clay mineral montmorillonite (Lim et al. 2013). Montmorillonite surface is hydrophilic and has low affinity for no polar liquids (Orucoglu \& Haciyakupoglu 2015). The positive inorganic cation on the surface of bentonite can be replaced with organic matter that changes the properties of its surface from hydrophilic to hydrophobic bentonite to obtain a highly efficient rate of adsorption of organic pollutants such as dyes, phenols and other environmental contaminants (Yan et al. 2015). Cetyl trimethyl ammonium bromide $(\mathrm{CTAB})$ is an organic material that can control the size and shape of alkaline particles and their properties and can reduce the surface tension of nanoparticles (Caglar et al. 2016). In this study, CTAB was chosen as a modified material for the bentonite surface to remove the dye solution. The factors influencing adsorption of a dye such as adsorbent dosage, solution $\mathrm{pH}$, initial concentration of dye solution and temperature have been evaluated. Meanwhile, kinetics, adsorption isotherms, and thermodynamics were also investigated to explore the adsorption mechanism of RR120 onto B-A-CTAB. Also, the effects of various inorganic anions ( such as $\mathrm{Cl}^{-}, \mathrm{SO}_{4}{ }^{2-}, \mathrm{CO}_{3}{ }^{2-}, \mathrm{NO}_{3}{ }^{-1}, \mathrm{HPO}_{3}{ }^{-3}$ ) on the decolourization efficiency were studied. 


\section{MATERIALS AND METHODS}

\section{Materials}

Reactive red 120 (RR 120) was obtained from Ciba uniqueness chemical compounds and used with none in addition purification. Cetrimonium bromide $\left(\mathrm{C}_{19} \mathrm{H}_{42} \mathrm{BrN}, \mathrm{CTAB}\right)$ was obtained from Chuchardt (Germany). $\mathrm{NaOH}$ and $\mathrm{H}_{2} \mathrm{SO}_{4}$ have been used to modify the $\mathrm{pH}$ which changed into bought from Appli Chem (GmbH). $\mathrm{AlCl}_{3}, \mathrm{NaCl}, \mathrm{Na}_{2} \mathrm{SO}_{4}, \mathrm{Na}_{2} \mathrm{CO}_{3}$, $\mathrm{Na}_{2} \mathrm{HPO}_{3} .5 \mathrm{H}_{2} \mathrm{O}$ and $\mathrm{NaNO}_{3}$ were obtained from Fluka. The raw bentonite was purchased from China. All solutions were prepared using distilled water.

\section{Preparation of Modified Bentonites}

At first, the raw bentonite was purified by dissolved $100 \mathrm{~g}$ of it in one litre of distilled water with stirring for 30 minutes. The solution was then left to settle for 20 minutes. After this process, the solid phase was separated by filtration, then washed with deionized water and dried in the oven at $303 \mathrm{~K}$. The bentonite was ground to obtain a powder and pure. In the second step, bentonites were activated by the aluminium hydroxide prepared by the following Eq. (1) (Yan et al. 2010).

$$
\mathrm{AlCl}_{3}+3 \mathrm{NaOH} \rightarrow \mathrm{Al}(\mathrm{OH})_{3}+3 \mathrm{NaCl}
$$

$\mathrm{Al}(\mathrm{OH})_{3}$ is added slowly to pure bentonite by a ratio (10 mmol Al/1.0 g bentonite) with a stirring at $303 \mathrm{~K}$ for 24 h. Finally, the modified bentonite by CTAB was prepared according to the references reported (Zhu et al. 2009). B-ACTAB was organized with the aid of including a certain quantity of CTAB solution to a 0.02 aqueous suspension of $20 \mathrm{~g}$ of $\mathrm{B}-\mathrm{Al}$ below moving. The suspension solution was heated for three hours at $313 \mathrm{~K}$, accrued with the aid of filtration, washed, dried at $353 \mathrm{~K}$ to constant mass, activated for $1 \mathrm{~h}$ at $413 \mathrm{~K}$, saved in a complete airtight plastic vial in a desiccator until addition use.

\section{Batch Experiments}

Adsorption of RR120 on modified bentonite turned into done in a batch gadget. A $50 \mathrm{~mL}$ RR120 solution $(50-150 \mathrm{mg} / \mathrm{L})$ within conical flasks. The aggregate was shaken using thermostatically achieve shaker right away. The shaker velocity worked at one hundred fifty rpm. The samples had been withdrawn $(6 \mathrm{~mL})$ at precise time periods $(5,10,15,20,30$, $45,60 \mathrm{~min}$ ), centrifuged for $10 \mathrm{~min}$ to detach the dye solution from the adsorbent, and evaluated for the colouration elimination efficiencies at $\lambda \max =535 \mathrm{~nm}$ using ultraviolet and visible spectroscopy (Japan; Optima Model SP - 3000; UV / VIS) geared up with a quartz cell of $1.0 \mathrm{~cm}$ path duration.

\section{Techniques used to Determine the Properties of Adsorbents}

The scanning electron microscope (SEM, Ties can Vega III Czech Republic) was used to study their surface morphology and Fourier transformed infrared spectrophotometer (IR Prestige - 21 Shimadzu) were performed in the range of $4000-500 \mathrm{~cm}^{-1}$ with $\mathrm{KBr}$ pellets. The X-ray diffraction (XRD) patterns of the sample were measured with Shimadzu Corporation Lab-X (XRD-6000) and recorded in the range of (3-80) deg with speed $5.0 \mathrm{deg} \mathrm{min}^{-1}$ and preset time $0.6 \mathrm{sec}$.

\section{RESULTS AND DISCUSSION}

\section{Analysis and Calculation}

Decolourization activity was expressed in all optimization study in terms of decolourization efficiency (\%), and it was calculated as follows:

Degradation efficiency $\%=\left[\left(\mathrm{C}_{0}-\mathrm{C}_{t}\right) / \mathrm{C}_{0}\right] \times 100 \% \quad \ldots(2)$

In which $\mathrm{C}_{0}\left(\mathrm{mg} \cdot \mathrm{L}^{-1}\right)$ is the initial concentration of dye and $C_{t}\left(m g . L^{-1}\right)$ is the concentration of dye of reaction time $\mathrm{t}$ (min).

$$
\mathrm{q}_{\mathrm{t}}=\left(\mathrm{C}_{0-} \mathrm{C}_{\mathrm{t}}\right) \mathrm{V} / \mathrm{W}
$$

Where $\mathrm{q}_{\mathrm{t}}\left(\mathrm{mg} \cdot \mathrm{g}^{-1}\right)$ is the quantity of RR120 dye adsorbed according to unit mass of adsorbent, $\mathrm{V}(\mathrm{L})$ is the volume of solution, and $\mathrm{W}(\mathrm{g})$ is the mass of the adsorbent.

\section{Adsorption Kinetics}

Two kinetic sorts the pseudo-first-order, and the pseudo-second-order have been used to suit into the experimental facts received from the colour removal steps. The Lagergren pseudo-first-order model is given by Eq. (4) (Fang et al. 2019):

$$
\log \left(\mathrm{q}_{\mathrm{e}}-\mathrm{q}_{\mathrm{t}}\right)=\log \mathrm{q}_{\mathrm{e}}-\mathrm{k}_{1} \mathrm{t} / 2.303
$$

Where in $\mathrm{qt}\left(\mathrm{mg} \mathrm{g}^{-1}\right)$ is the adsorption ability at time $\mathrm{t}$, $\mathrm{q}_{\mathrm{e}}\left(\mathrm{mg} \mathrm{g}^{-1}\right)$ is the adsorption potential at equilibrium, and $\mathrm{k}_{1}$ $\left(\mathrm{min}^{-1}\right)$ represents the rate constant of the pseudo-first-order version. Eq. (5) is the pseudo-second-order (Wang \& Wu 2006) defined as follows:

$$
\mathrm{t} / \mathrm{q}_{\mathrm{t}}=1 / \mathrm{k}_{2} \mathrm{q}_{\mathrm{e}}^{2}+\mathrm{t} / \mathrm{q}_{\mathrm{e}}
$$

Where $\mathrm{k}_{2}\left(\mathrm{~L} \mathrm{mg}^{-1} \mathrm{~min}^{-1}\right)$ is the rate constant of the pseudo-second-order model.

\section{Adsorbent Characterization}

FTIR spectroscopy is a touchy approach to probe the interaction kind configuration and topical environment of the surfactant cations within the interlamellar vicinity of bentonite (Luo et al. 2019). The comparative FTIR spectra of P-Bent, P-Bent-Al and P-Bent-Al-CTAB are shown in Fig. 1. The band at $3622 \mathrm{~cm}^{-1}$ assigned to stretching vibrations of structural OH groups (Tomic et al. 2015), whereas the bands at 3441 and $1639 \mathrm{~cm}^{-1}$ can be assigned to the $\mathrm{O}-\mathrm{H}$ deformation 


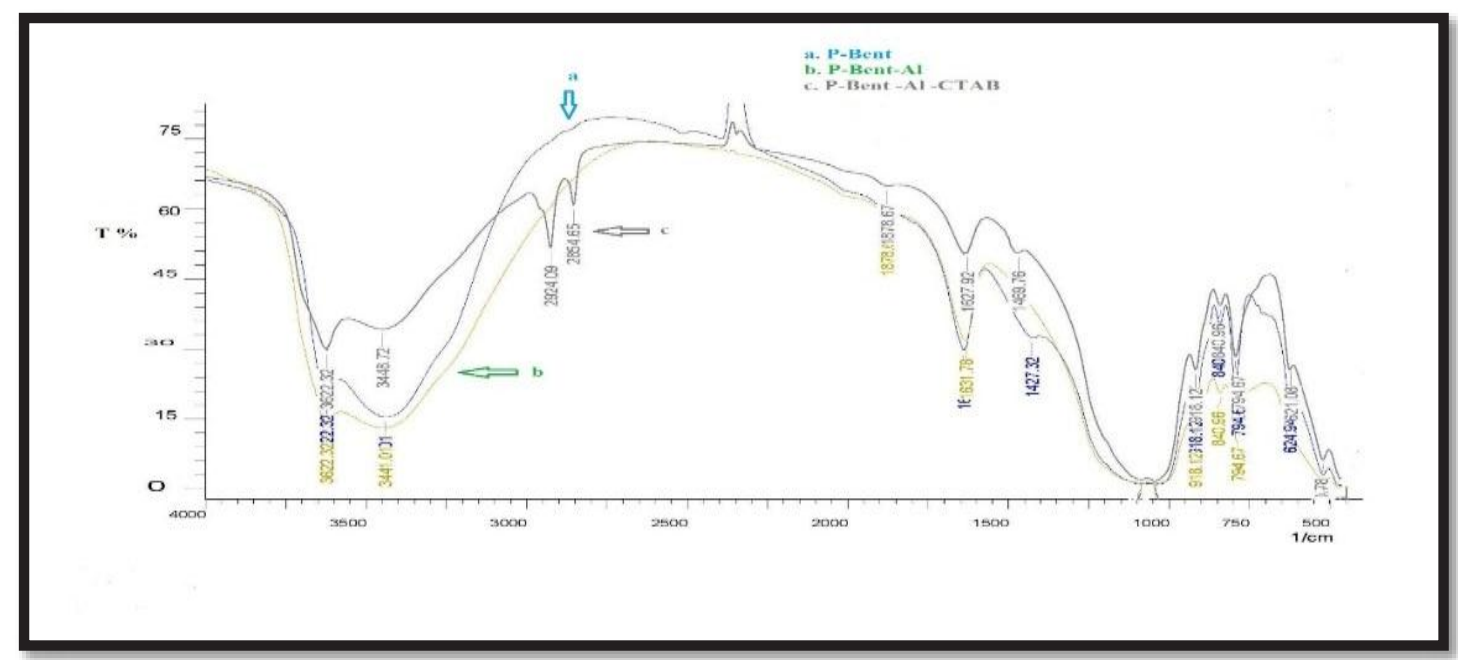

Fig.. 1: FTIR spectra of a. P-Bent, b. P-Bent-Al and c. P-Bent-Al-CTAB.

of water (Ayodele \& Hameed 2013). The Si-O stretching vibrations are shown at 1088 and $1042 \mathrm{~cm}^{-1}$, respectively (Tomic et al. 2015). The band absorption at $918 \mathrm{~cm}^{-1}$ can be assigned to the deformation of $\mathrm{Al}-\mathrm{Al}-\mathrm{OH}$ in the octahedral layers (Ayodele \& Hameed 2013). Coupled Al-O/Si-O appeared at $(841,795,625) \mathrm{cm}^{-1}$ and Al-O-Si deformations appeared at $521 \mathrm{~cm}^{-1}$, indicating the existence of the essential structure of bentonite (Tomic et al. 2015). In FTIR spectra of $\mathrm{B}-\mathrm{Al}$ a considerable growth within the density of the bands at 3410 and $1636 \mathrm{~cm}^{-1}$ of sorbed water molecules, due to the creation of hydroxy-aluminium cations increasing large quantities of water and hydroxyl. However, a considerable reduction in the intensities of these two bands while CTAB cations had been introduced (Ayodele \& Hameed 2013).

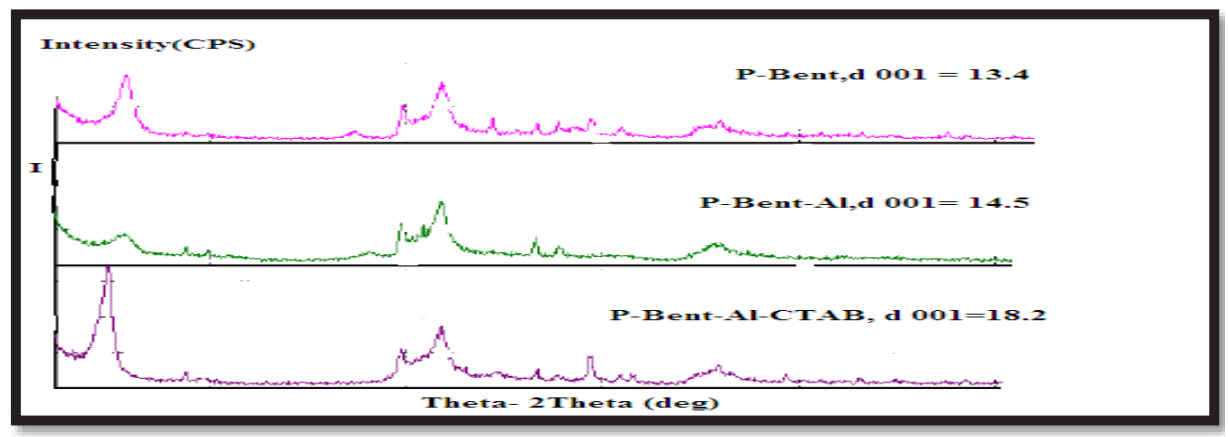

Fig. 2: XRD modality of behaviour the adsorbent.

A

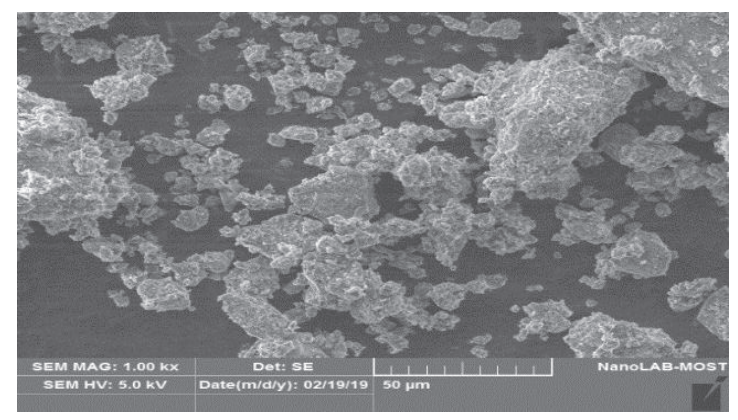

B

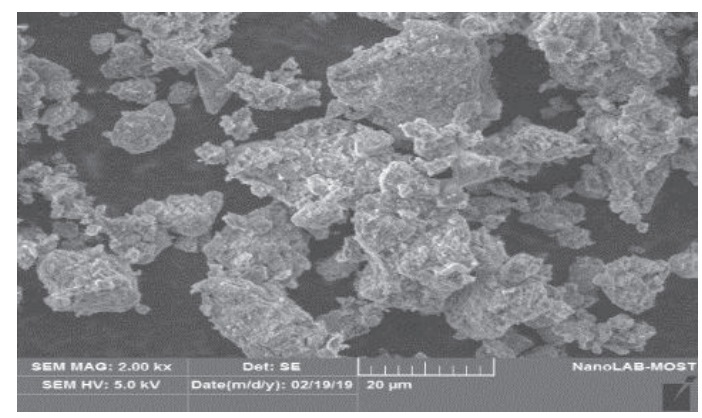

Fig. 3: SEM photos of the adsorbents. (A) Pure Bentonite, and (B) P-B-A-CTAB. 
The bands at (2928 and 2855) $\mathrm{cm}^{-1}$ had been observed for B-A-CTAB. They could be indicated to the anti-symmetric and symmetric stretching vibration modes of $-\mathrm{CH}_{3}$ and $-\mathrm{CH}_{2}$ similarly, the bending vibration of $-\mathrm{CH}_{3}$ was observed at $1470 \mathrm{~cm}^{-1}$ in organic intercalator. XRD assessment comes to be done which will pick out the mineralogical shape of the supported bentonite adsorbents and the XR-Diffraction styles are verified in Fig. 2. It may be visible that comparable diffraction peaks attributable to the complicated additives of adsorbents had been detected in those three samples. The principle crystalline phases determined in pure-Ben for $\mathrm{SiO}_{2}$, located at $2 \theta$ (Theta) of $6.61^{\circ}, 19.6^{\circ}, 21.69^{\circ}, 26.59^{\circ}$, $36.71^{\circ}$ and $62.04^{\circ}$, which have been consistent with that of the literature mentioned (Tiwari et al. 2011). The boom of basal wideness from $13.4 \mathrm{~A}^{\circ}$ for pure-Bent to $18.2 \mathrm{~A}^{\circ}$ for $\mathrm{B}-\mathrm{A}-\mathrm{CTAB}$ changed into due to the competing of $\mathrm{Al}$ and $\mathrm{CTAB}$ molecule into the interlayer distance area of pureBent that increased its interlayer spacing and later confirmed RR120 adsorption potential, which changed into, also assured via FTIR. SEM photographs of the adsorbents are given in Fig. 3. Even though it was no longer possible to precisely limit the particle size of the adsorbents, big aggregates of platelets component with small particles, especially among 20 and 50 micrometres in length and have been determined for the pure bent. Under the modification, the average particle size reduces; smell and properly unattached particles can be located, particularly for B-A-CTAB. This commentary advised that some disaggregation of bentonite particles happened for the duration of the modification.

\section{Effect of Different Factors on the Decolorization Efficiency of RR120}

Comparison of various adsorbents: An experiment was performed to compare three adsorbents on the dye solution. Fig. 4 shows the efficiency of colour removal over time. The decolourization efficiency is high for the Bent-Al-CTAB up to $93 \%$ in 30 minutes and is higher than pure bentonite and activated by aluminium. Bentonite pure isn't a powerful adsorbent for the organic compounds in water. These results show that the modified bentonites' ability to remove the colour of the dye solution has been strongly enhanced after surface modification, as surface properties have changed from hydrophilic to hydrophobic form (Xu et al. 2017). Modified bentonite was used in further studies.

Effluence of adsorbent dosage: Fig. 5 shows the effect of changing bentonite modified dose on the decolourization efficiency of dye solution. It was found the efficiency of removal of the colour increases with the increase of the dose

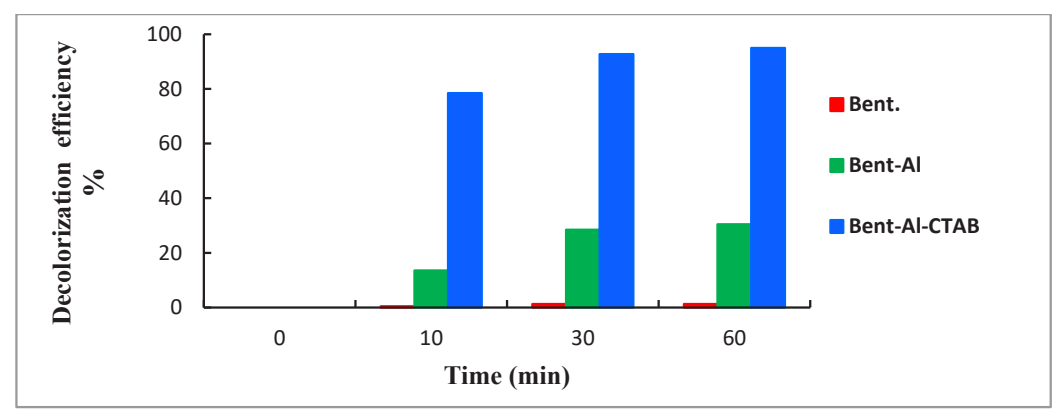

Fig. 4: Assessment of the three adsorbent on decolorization performance (adsorbent dosage: $0.1 \mathrm{~g}$, temperature: $303 \mathrm{~K}, \mathrm{pH}=6.0, \mathrm{rpm}=150$ and RR120 concentration: $\left.96 \mathrm{mg} \cdot \mathrm{L}^{-1}\right)$.

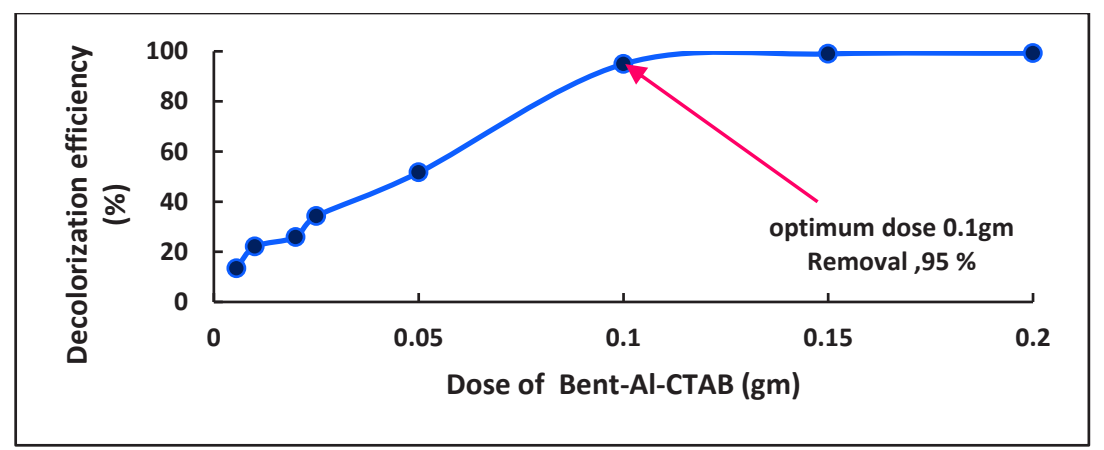

Fig. 5: Effect of adsorbent dosage on decolorization efficiency: (temperature $303 \mathrm{~K}, \mathrm{pH}=6, \mathrm{rpm}=150$, contact time $=60 \mathrm{~min}$ and RR120 concentration: $96 \mathrm{mg} \cdot \mathrm{L}^{-1}$ ). 
of bentonite modified, but it is not necessary to use a dose greater than $0.1 \mathrm{gm}$ because the decolourization efficiency was not affected greatly. When the dose of B-A-CTAB is $0.1 \mathrm{~g}$, the efficiency of colour removal reached $95 \%$. Thus this amount of the modified bentonite has been used for the next experiments.

Effluence of pH: For the purpose to take a look at the effect of $\mathrm{pH}$ on the adsorption potential of B-Al-CTAB, acidic $\mathrm{pH}$ 3.5 and alkaline $\mathrm{pH} 9.0$ and previously studied $\mathrm{pH} 6.0$ were selected (Fig. 6). The efficiency of removal (91\%, 80\% and $47 \%)$ was obtained for $\mathrm{pH}(3.5,6$ and 9) respectively, at contact time 10 minutes. Low degradation efficiency with $\mathrm{pH}$ increase may be due to that the $\mathrm{pH}$ affected the surface charge of the adsorbent and the degree of ionization of adsorbate (Xu et al. 2017). At lower $\mathrm{pH}$, the protonation of surface -OH groups to $-\mathrm{OH}_{2}{ }^{+}$(Bouzid et al. 2015), consequently the positive sites increased, thereby electrostatic attraction enhanced between the positively charged adsorption sites and negatively charged dyes. In alkaline condition, the protonation of surface-OH decreased and consequently, the positive sites decreased, and on the other hand, the abundance of $\mathrm{OH}^{-}$ions competing with the anionic dye for adsorption sites, resulted in the reduction of exchangeable dye anionic on the adsorbent (Bouzid et al. 2015).
Effect of primary dye concentration: Preliminary concentration of dyes is a good-sized parameter for sensible inspiration. Therefore, it is vital to have a look at the effect on the primary dye concentration, and the effects are shown Fig. 7. It indicates elevated colour elimination performance with decreased concentration of dye RR120. As the concentration of dye lowers from $150 \mathrm{mg} . \mathrm{L}^{-1}$ to 50 $\mathrm{mg} . \mathrm{L}^{-1}$, the decolourization performance of dye grows from $48 \%$ to $93 \%$ within 15 min of the adsorption process. The degradation performance of dye reduced as the preliminary concentration increased, this brings about the settlement with proposed whilst the positioned range of susceptible sites, the competitive adsorption might contact the adsorption and degradation of contaminants on the surface of particles, and further reduce the reaction velocity (Jafari et al. 2016).

Study of adsorption kinetics: Two kinetic models pseudo-first-order and pseudo-second-order have been used to fit the experimental data points obtained from the decolourization processes. An assessment of the consequences with the precise line is plotted in Figs. 8 and 9 and the kinetic parameters are summarized in Table 1 . The $\left(\mathrm{R}^{2}\right)$ correlation coefficients of the pseudo-first-order version are lower than the ones of the pseudo-second-order model, and the calculated $\left(\mathrm{q}_{\mathrm{e}}\right)$ adsorption potential at equilibrium appeared to be

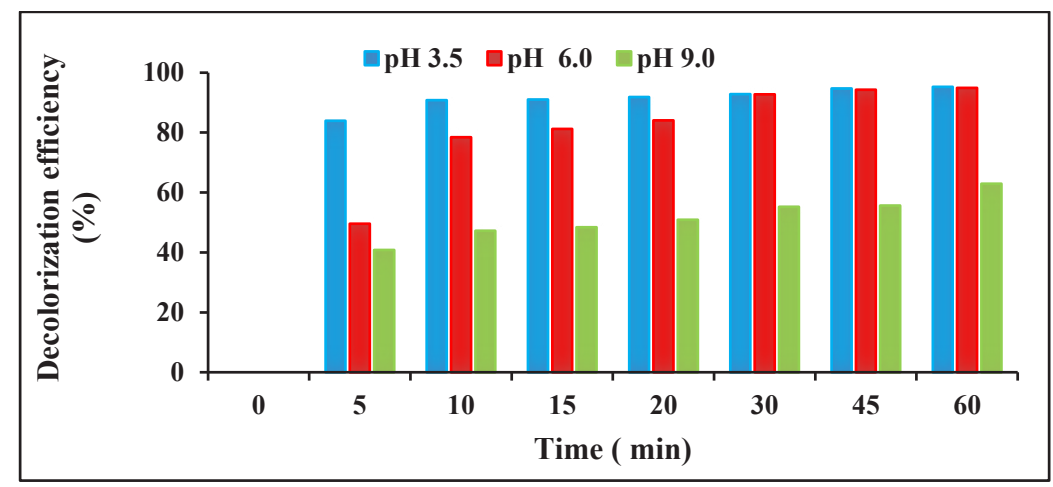

Fig. 6: Effect of initial pH on decolorization efficiency (303K, adsorbent dosage $=0.1 \mathrm{~g}, \mathrm{rpm}=150$ and RR120 concentration: 96 mg. $\mathrm{L}^{-1}$ ).

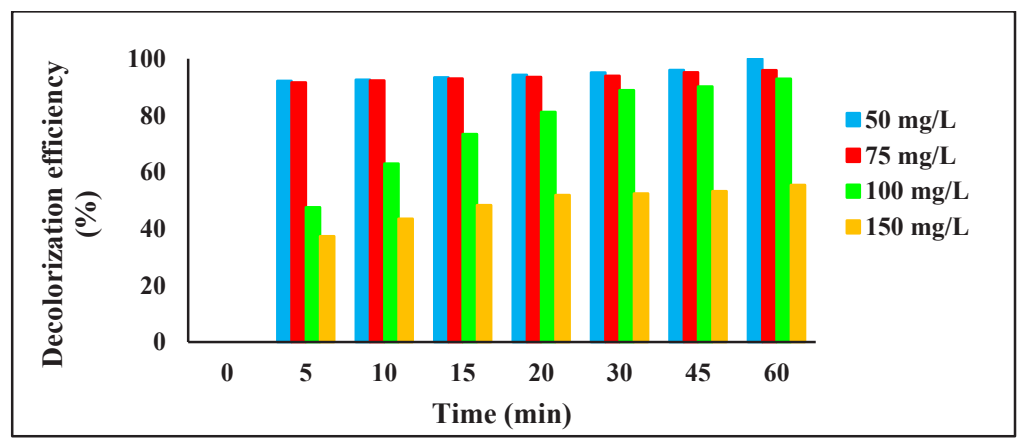

Fig. 7: Effect of variations in initial dye concentration on the decolorization efficiency $(\mathrm{pH}=6.0,303 \mathrm{~K}$, adsorbent dosage $=0.1 \mathrm{~g}, \mathrm{rpm}=150)$. 
near the empirical values, indicating that pseudo 2 nd order model version yields a higher match to the empirical data than the pseudo-first-order model. Comparable outcomes were pronounced for the adsorption of AGYG, AB93, ATBA and AB25 onto B-A-CTAB (Yan et al. 2015).

Effect of temperature and adsorption isotherms: The effect of temperature on the adsorption process is an important parameter and should be studied. As can be observed in Fig. 10 , the removal rate for RR 120 was enhanced by increasing the temperature from $293 \mathrm{~K}$ to $303 \mathrm{~K}$ and the colour removal from $60 \%$ and $81 \%$ respectively was achieved at $15 \mathrm{~min}$ of the adsorption process. This increase can be attributed to faster mass transfer in solution and increased collision frequencies between adsorbents and dye molecules. However, removal efficiency decreased as temperature increased further to $313 \mathrm{~K}$ and $323 \mathrm{~K}$ indicating that the RR120 adsorption on modified bentonite is exothermic by nature and these results are similar in previous reports (Yan et al. 2010).

The Langmuir and Freundlich isotherms were used and expressed by Eqs. (6) and (7) respectively.

Table 1: The kinetic parameters for Reactive red 120 on modified bentonite.

\begin{tabular}{|c|c|c|c|c|c|c|c|c|}
\hline \multirow[t]{2}{*}{$\mathrm{T}(\mathrm{k})$} & \multirow{2}{*}{$\begin{array}{l}\mathrm{C}_{\mathrm{o}} \\
\left(\mathrm{mg} \cdot \mathrm{L}^{-1}\right)\end{array}$} & \multirow{2}{*}{$\begin{array}{l}\text { qe. exp } \\
\left(\mathrm{mg} . \mathrm{L}^{-1}\right)\end{array}$} & \multicolumn{6}{|c|}{ Pseudo-first-order model Pseudo-second-order model } \\
\hline & & & $\begin{array}{l}\mathrm{q}_{1 \mathrm{e}} \\
\left(\mathrm{mg} \cdot \mathrm{g}^{-1}\right)\end{array}$ & $\begin{array}{l}\mathrm{k}_{1} \\
\left(\min ^{-1}\right)\end{array}$ & $\mathrm{R}^{2}$ & $\begin{array}{l}\mathrm{q}_{2 \mathrm{e}} \\
\left(\mathrm{mg} \cdot \mathrm{g}^{-1}\right)\end{array}$ & $\begin{array}{l}\mathrm{k}_{2} \\
\left(\mathrm{~g} \cdot \mathrm{mg}^{-1} \cdot \mathrm{min}^{-1}\right)\end{array}$ & $\mathrm{R}^{2}$ \\
\hline \multirow[t]{4}{*}{303} & 50 & 25.30 & 1.99 & 0.0217 & 0.9858 & 25.38 & 0.0426 & 0.9994 \\
\hline & 75 & 26.30 & 2.43 & 0.0596 & 0.9284 & 26.50 & 0.0601 & 0.9999 \\
\hline & 100 & 46.96 & 29.78 & 0.0744 & 0.9520 & 51.81 & 0.0033 & 0.9990 \\
\hline & 150 & 46.40 & 12.50 & 0.0380 & 0.8084 & 47.62 & 0.0074 & 0.9082 \\
\hline 293 & 96 & 45.13 & 80.50 & 0.1239 & 0.8956 & 55.60 & 0.0017 & 0.9890 \\
\hline 313 & 96 & 46.30 & 20.72 & 0.1078 & 0.7558 & 52.63 & 0.0040 & 0.9940 \\
\hline 323 & 96 & 38.13 & 42.34 & 0.0857 & 0.9493 & 43.84 & 0.0030 & 0.9840 \\
\hline
\end{tabular}
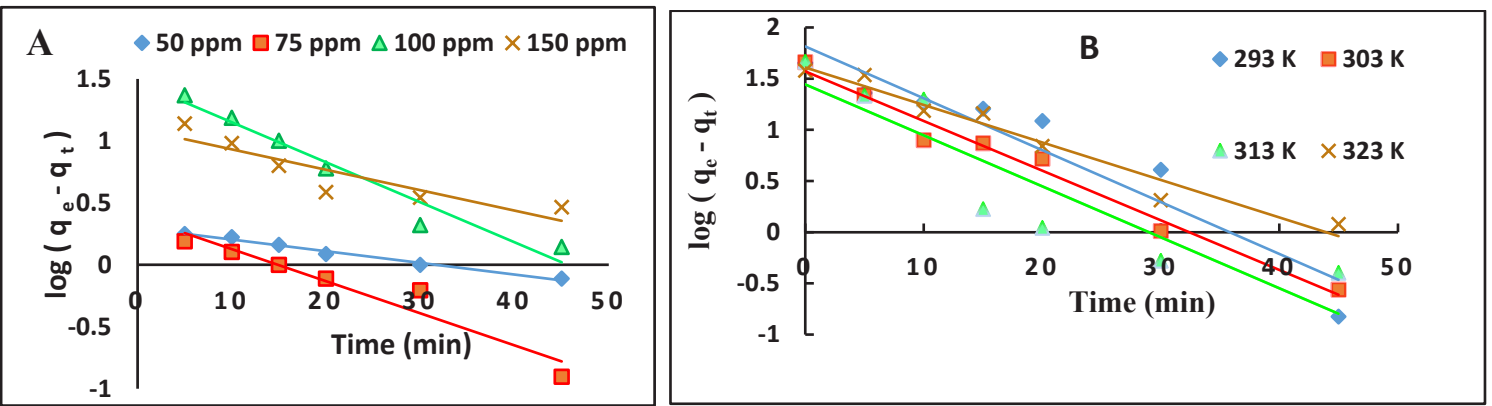

Fig. 8: The pseudo-first-order kinetics plots for the adsorption of RR120 onto Bent-Al-CTAB at (A) diverse RR120 preliminary concentrations and (B) various temperatures.
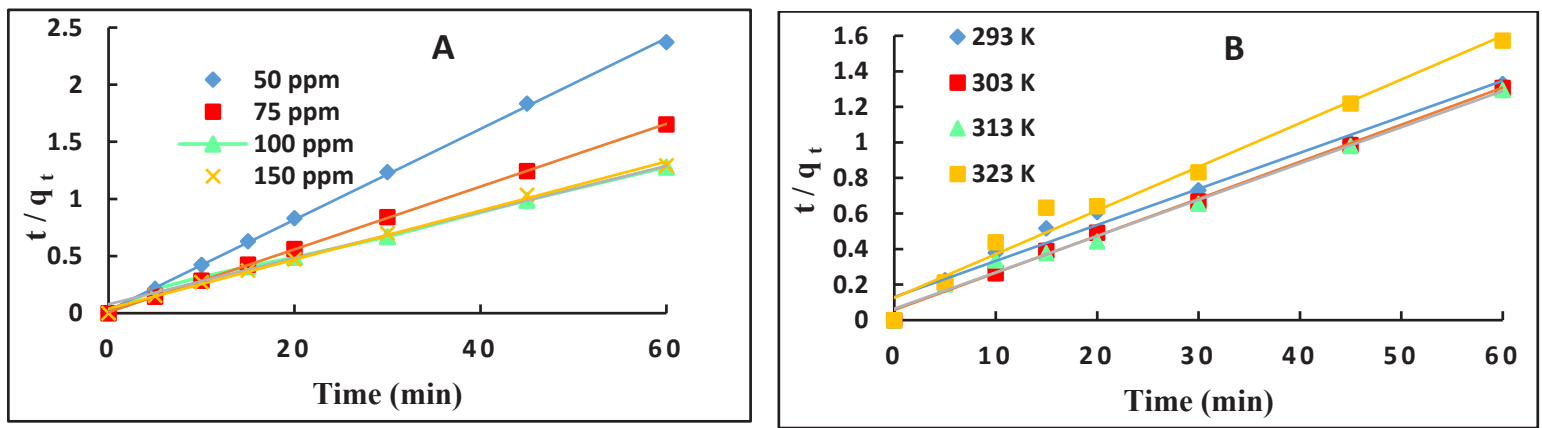

Fig. 9: The pseudo-second-order kinetics draws for the adsorption of RR120 onto B-A-CTAB at (A) many RR120 initial concentrations and $(\mathrm{B})$ various temperatures. 


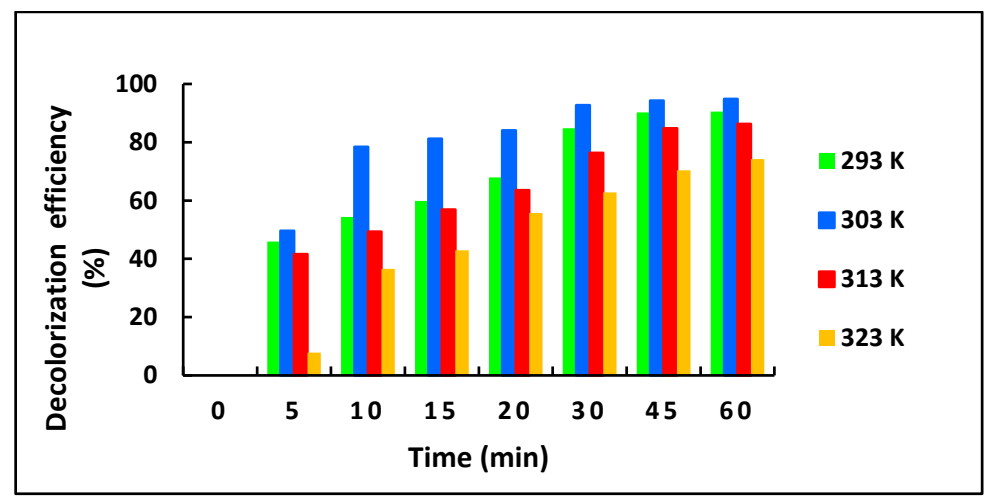

Fig. 10: Influence of variations in temperature on the decolorization efficiency $(\mathrm{pH}=6.0$, adsorbent dosage $=0.1 \mathrm{~g}, \mathrm{rpm}=150$ and RR120 concentration $\left.=96 \mathrm{mg} \cdot \mathrm{L}^{-1}\right)$.

$$
\begin{gathered}
\mathrm{C}_{\mathrm{e}} / \mathrm{q}_{\mathrm{e}}=1 / \mathrm{K}_{\mathrm{L}} \mathrm{q}_{\mathrm{m}}+\mathrm{C}_{\mathrm{e}} / \mathrm{q}_{\mathrm{m}} \\
\ln _{\mathrm{e}}=\ln \mathrm{K}_{\mathrm{F}}+(1 / \mathrm{n}) \ln \mathrm{C}_{\mathrm{e}}
\end{gathered}
$$

Where, $\mathrm{q}_{\mathrm{e}}\left(\mathrm{mg} \cdot \mathrm{g}^{-1}\right)$ and $\mathrm{q}_{\mathrm{m}}\left(\mathrm{mg} \cdot \mathrm{g}^{-1}\right)$ are the equilibrium adsorption quantity at the adsorbate and the monolayer saturation adsorption quantity on the adsorbent, zrespectively. Ce $\left(\mathrm{mg} . \mathrm{L}^{-1}\right)$ is the equilibrium concentration of adsorbate. $\mathrm{K}_{\mathrm{L}}$ and $\mathrm{K}_{\mathrm{F}}$ are the Langmuir and Freundlich isotherm constant, respectively. The suitable lines are plotted in Fig. 11 and the isotherm parameters are

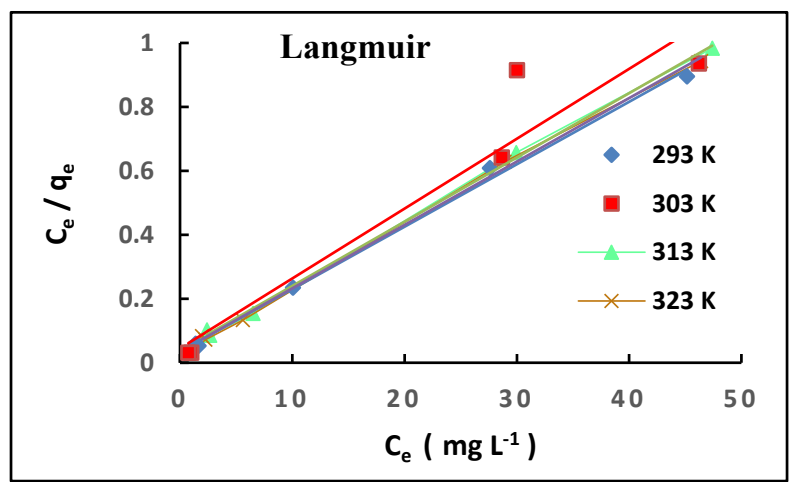

summarized in Table 2. The correlation coefficients $\left(\mathrm{R}^{2}\right)$ of Langmuir isotherm had been better than that of Freundlich isotherms, and the monolayer saturation adsorption amount $\left(\mathrm{q}_{\mathrm{m}}\right)$ changed closer to the calculated value $\left(\mathrm{q}_{\mathrm{e}, \max }\right)$, indicating that the Langmuir isotherm outfitted fine to the experimental information, and the monolayer coverage nature of the adsorbate on the surface of B-A-CTAB (Karaca et al. 2008).

Study thermodynamic of the adsorption process:

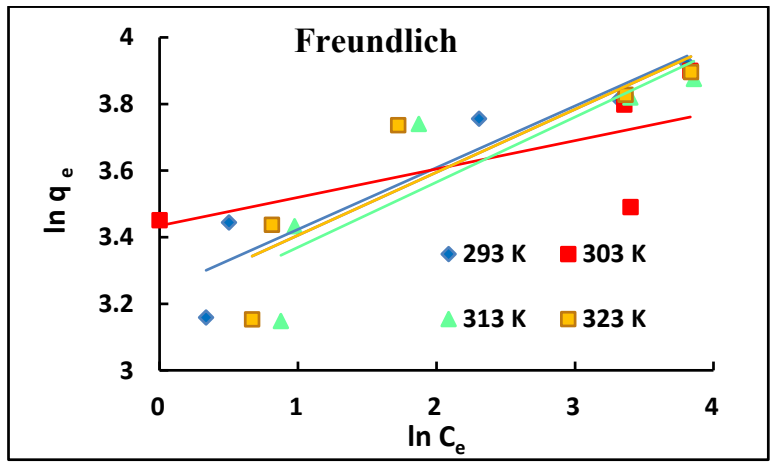

Fig. 11: Langmuir and Freundlich isotherms for Reactive red 120 adsorption on modified bentonite.

\begin{tabular}{|c|c|c|c|c|c|}
\hline \multirow[t]{2}{*}{ Model } & \multirow[t]{2}{*}{ Parameters } & \multicolumn{4}{|l|}{$\mathrm{T}(\mathrm{K})$} \\
\hline & & 293 & 303 & 313 & 323 \\
\hline \multirow[t]{3}{*}{ Langmuir } & $\mathrm{q}_{\mathrm{m}}\left(\mathrm{mg} \cdot \mathrm{g}^{-1}\right)$ & 51.28 & 45.66 & 49.75 & 50.51 \\
\hline & $\mathrm{K}_{\mathrm{L}}\left(\mathrm{L} \cdot \mathrm{mg}^{-1}\right)$ & 0.0007 & 0.001 & 0.0008 & 0.0006 \\
\hline & $\mathrm{R}^{2}$ & 0.9965 & 0.9231 & 0.9987 & 0.9986 \\
\hline \multirow[t]{3}{*}{ Freundlich } & $\mathrm{n}$ & 5.397 & 11.737 & 5.115 & 5.291 \\
\hline & $\mathrm{K}_{\mathrm{F}}$ & 25.485 & 31.016 & 23.098 & 24.953 \\
\hline & $\mathrm{R}^{2}$ & 0.8898 & 0.4613 & 0.7690 & 0.7890 \\
\hline
\end{tabular}

Table 2: The isotherm parameters for RR120 adsorption on modified bentonite. 
Table 3: Thermodynamic functions for RR120 adsorption on modified bentonite.

\begin{tabular}{|lllll|}
\hline $\mathrm{T}(\mathrm{K})$ & $\mathrm{K}_{\mathrm{C}}$ & $\begin{array}{l}\Delta \mathrm{G}^{0} \\
\left(\mathrm{KJ} \mathrm{mol}^{-1}\right)\end{array}$ & $\begin{array}{l}\Delta \mathrm{S}^{0} \\
\left(\mathrm{~J} \mathrm{~mol}^{-1} \mathrm{~K}^{-1}\right)\end{array}$ & $\begin{array}{l}\Delta \mathrm{H}^{0} \\
\left(\mathrm{KJ} \mathrm{mol}^{-1}\right)\end{array}$ \\
\hline 303 & 126.47 & -11.62 & -93.78 & -40.1 \\
313 & 38.83 & -10.68 & & \\
323 & 48.03 & -9.74 & & \\
\hline
\end{tabular}

Thermodynamic functions such as free energy change $\left(\Delta \mathrm{G}^{\circ}\right)$, enthalpy change $\left(\Delta \mathrm{H}^{\circ}\right)$ and entropy change $\left(\Delta \mathrm{S}^{\circ}\right)$ have been evaluated and can be calculated from Esq. (8)(10), respectively:

$$
\begin{gathered}
\mathrm{Ln} \mathrm{K}_{\mathrm{c}}=-\Delta \mathrm{H}^{0} / \mathrm{RT}+\Delta \mathrm{S}^{0} / \mathrm{R} \\
\mathrm{K}_{\mathrm{c}}=\mathrm{C}_{\mathrm{AE}} / \mathrm{C}_{\mathrm{SE}} \\
\Delta \mathrm{G}^{0}=\Delta \mathrm{H}^{0}-\mathrm{T} \Delta \mathrm{S}^{0}
\end{gathered}
$$

Where, $\mathrm{K}_{\mathrm{c}}$ is the equilibrium constant, $\mathrm{R}\left(8.314 \mathrm{~J} \mathrm{~mol}^{-1}\right.$ $\mathrm{K}^{-1}$ ) and $\mathrm{T}(\mathrm{K})$ are ideal gas constants and thermodynamic temperature, respectively. $\mathrm{C}_{\mathrm{AE}}$ is the quantity of dye $(\mathrm{mg})$ adsorbed on the adsorbent per $\mathrm{L}$ of the solution at equilibrium. $\mathrm{C}_{\mathrm{SE}}$ is the equilibrium concentration (mg. $\mathrm{L}^{-1}$ ) of the dye solution. The thermodynamic parameters are summarized in Table 3. The negative $\Delta \mathrm{G}^{\circ}$ and $\Delta \mathrm{H}^{\circ}$ indicated the adsorption was spontaneous and exothermic, the rise of temperature was not conducive to the adsorption process, which was consistent with the experimental results. Whereas, negative $\Delta S^{\circ}$ showed that the adsorption was entropy decrease process. Adsorption dye molecules become constrained by their association with surface atoms. In doing so, they lose some degrees of freedom compared to their pre-adsorption status. Consequently, it decreases in free energy and entropy decreases in enthalpy.

Effect of the salt: The effect of the salt on the elimination performance of RR 120 adsorption on modified bentonite become tested through the usage of the extraordinary salts as $\mathrm{NaCl}, \mathrm{Na}_{2} \mathrm{SO}_{4}, \mathrm{Na}_{2} \mathrm{CO}_{3}, \mathrm{NaNO}_{3}$, and $\mathrm{Na}_{2} \mathrm{HPO}_{3} .5 \mathrm{H}_{2} \mathrm{O}$ (Fig. 12). The results show that the presence of $\mathrm{NaCl}$ and $\mathrm{NaNO}_{3}$ enhances the decolourization efficiency. Whilst the presence of $\mathrm{Na}_{2} \mathrm{SO}_{4}, \mathrm{Na}_{2} \mathrm{CO}_{3}$ and $\mathrm{Na}_{2} \mathrm{HPO}_{3} .5 \mathrm{H}_{2} \mathrm{O}$ decrease the decolourization effectiveness because $\mathrm{SO}_{4}{ }^{2-}, \mathrm{CO}_{3}{ }^{2-}$ and $\mathrm{HPO}_{3}{ }^{2-}$ ions compete with dye molecules and occupy the reactive places on modified bentonite surface (Sribenja \& Saikrasun 2015).

\section{CONCLUSIONS}

The activated bentonite was modified by CTAB then confirmed by techniques FTIR, X-ray diffraction and SEM. The second-order kinetic model can well explain the dye degradation process using B-A-CTAB. The Langmuir isotherm had been better than that of Freundlich isotherms. The presence of $\mathrm{NaNO}_{3}$ and $\mathrm{NaCl}$ enhances the decolourization efficiency while the ions $\mathrm{SO}_{4}{ }^{2-}, \mathrm{CO}_{3}{ }^{2-}$ and $\mathrm{HPO}_{3}{ }^{-2}$ were inhibiting the process of dye removal.

\section{REFERENCES}

Ayodele, O. B. and Hameed, B. H. 2013. Synthesis of copper pillared bentonite ferri oxalate catalyst for degradation of 4-nitrophenol in visible light assisted Fenton process. J. Ind. Eng. Chem., 19: 966-974.

Bouzid, S., Khenifi, A., Bennabou, K. A., Trujillano, R., Vicente, M. A. and Derriche, Z. 2015. Removal of Orange II by phosphonium-modified Algerian Bentonites. Chem. Eng. Commun., 202: 520-533.

Caglar, B., Topcu, C., Coldur, F., Sarp, G., Caglar, S., Tabak, A. and Sahin, E. 2016. Structural, thermal, morphological and surface charge properties of dodecyl trimethyl ammonium-smectite composites. J. Mol. Struct., 1105: 70-79.

Engin, A. B., Ozdemir, O., Turan, M. and Turan, A. Z. 2008. Color removal from textile dye bath effluents in a zeolite fixed bed reactor: determination of optimum process conditions using Taguchi method. Hazard. Mater., 159: 348-353.

Fan, Y., Liu, H. J., Zhang, Y. and Chen, Y. 2015. Adsorption of anionic $\mathrm{MO}$ or cationic MB from MO/MB mixture using polyacrylonitrile fiber hydrothermally treated with hyper-branched polyethylenimine. J. Hazard. Mater., 283: 321-328.

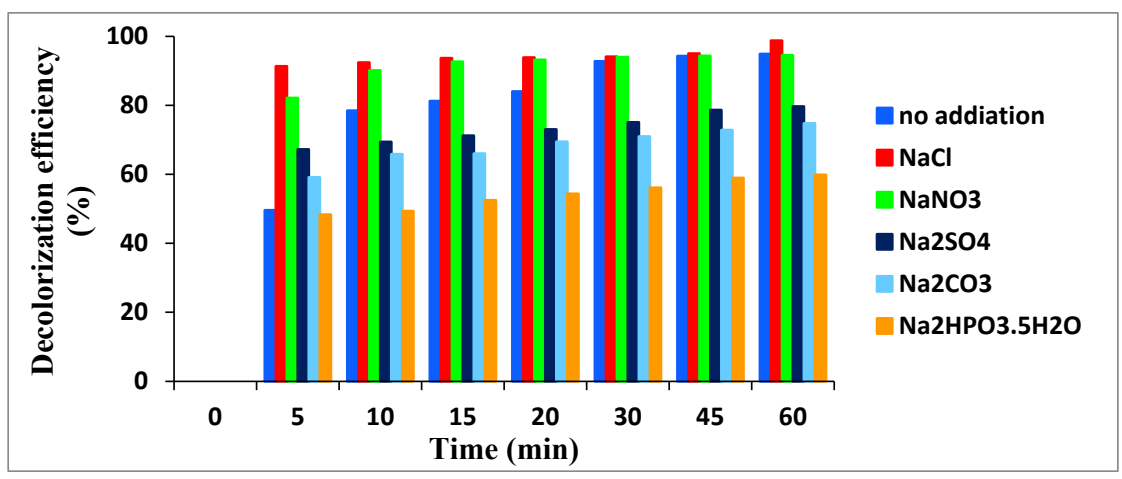

Fig. 12: Influence of addition of 0.01 inorganic salts on RR120 decolorization efficiency $(\mathrm{pH}=6.0$, adsorbent dosage $=0.1 \mathrm{~g}, \mathrm{rpm}=150$ and RR120 concentration $\left.=96 \mathrm{mg} \cdot \mathrm{L}^{-1}\right)$. 
Fang, S., Yang, N., Qiu, M. and Huang, C. 2019. Degradation of dye C.I. Reactive red 15 in aqueous solution by kaolinite supported zero valent iron. Nat. Environ. Pollut. Technol., 18(3): 963-968.

Giri, S. K., Das, N. N. and Pradhan, G. C. 2011. Magnetite powder and kaolinite derived from waste iron ore tailings for environmental applications. Powder Technol., 214: 513-518.

Giustetto, R. and Wahyudi, O. 2011. Sorption of red dyes on palygorskite: synthesis and stability of red/purple Mayan nano composites. Microporous Mesoporous Mater., 142: 221-235.

Hameed, B. H., Ahmad, A. A. and Aziz, N. 2007. Isotherms, kinetics and thermodynamics of acid dye adsorption on activated palm ash. Chem. Eng. J., 133: 195-203.

Jafari, S., Tryba, B., Kusiak-Nejman, E., Kapica-Kozar, J., Morawski, A. W. and Sillanpaa, M. 2016. The role of adsorption in the photocatalytic decomposition of Orange II on carbon-modified $\mathrm{TiO}_{2}$. J. Mol. Liq., 220: 504-512.

Karaca, S., Gurses, A., Acikyildiz, M. and Ejder, M. 2008. Adsorption of cationic dye from aqueous solutions by activated carbon. Micropor. Mesopor. Mat., 115: 376-382.

Konicki, W., Sibera, D., Mijowska, E., Lendzion-Bielun, Z. and Narkiewicz, U. 2013. Equilibrium and kinetic studies on acid dye Acid Red 88 adsorption by magnetic $\mathrm{ZnFe}_{2} \mathrm{O}_{4}$ spinel ferrite nanoparticles. J. Colloid Interface Sci., 3: 152-160.

Lim, S., Gomes, C. and AbKadir, M. 2013. Characterizing of bentonite with chemical, physical and electrical perspective for improvement of electrical grounding systems. Int. J. Electrochem. Sci., 8: 11429-11447.

Luo, J., Zhao, D., Wang, L., Asiri, A.M. and Alamary, K.A. 2019. Simultaneous removal of $\mathrm{Cu}$ (II) and 1- naphtha in wastewater by magnetic nanoparticle-grapheme oxide composites. Nat. Environ. Pollut. Technol., 18(3): 777-787.

Orucoglu, E. and Haciyakupoglu, S. 2015. Bentonite modification with hexadecyl pyridinium and aluminum polyoxy cations and its effectiveness in Se(IV) removal. J. Environ. Manage., 160: 30-38.

Qiu, M. 2019. Degradation of azo dye acid orange 7 by zero valent activated with potassium persulphate. Nat. Environ. Pollut. Technol., 18(1): 197-201.
Sribenja, S. and Saikrasun, S. 2015. Adsorption behavior and kinetics of Lac dyeing on poly (ethylene mine) - treated bamboo fibers. Fiber. Polym., 16: 2391-2400.

Suba, V. and Rathika, G. 2016. Novel adsorbents for the removal of dyes and metals from aqueous solution- A review. J. Adv. Phys., 5: 277-294.

Tiwari, D., Laldanwngliana, C., Choi, C. H. and Lee, S. M. 2011. Manganese- modified natural sand in the remediation of aquatic environment contaminated with heavy metal toxic ions. Chem. Eng. J., 171: 958-966.

Tomic, Z. P., Asanin, D. P., Durovic-pejcev, R., Dordevic, A. and Makreski, P. 2015. Adsorption of acetochlor herbicide on inorganic-and organicmodified bentonite monitored by mid-infrared spectroscopy and batch adsorption. Spectrosc. Lett., 48: 685-690.

Wang, S. B. and Wu, H. W. 2006. Environmental-benign utilization of fly ash as low-cost adsorbents. J. Hazard. Mater., 136: 482-501.

Xu, D., Li, W., Wang, K., Bai, Y., Lin, Q. and Gao, M. 2017. Hydroxy aluminum and cetyl trimethyl ammonium bromide modified bentonite as adsorbent and its adsorption for Orange II. J. Des. Water. Trea., 94: 244-253.

Yan, L. G., Xu, Y. Y., Yu, H. Q., Xin, X. D., Wei, Q. and Du, B. 2010. Adsorption of phosphate from aqueous solution by hydroxyl-aluminum, hydroxy-iron and hydroxy-iron-aluminum pillared bentonites. J. Hazard. Mater., 179: 244-250.

Yan, L., Qin, L., Yu, H., Li, S., Shan, R. and Du, B. 2015. Adsorption of acid dyes from aqueous solution by CTMAB modified bentonite: Kinetic and isotherm modeling. J. Mol. Liq., 211: 1074-1081.

Zhang, J. and Qiu, M. 2019. Adsorption kinetics and isotherms of copper ion in aqueous solution by bentonite supported nano scale zero valent iron. Nat. Environ. Pollut.Technol., 18(1): 269-274.

Zhang, Y. J., Liu, L. C., Ni, L. L. and Wang, B. L. 2013. A facile and lowcost synthesis of granulated blast furnace slag-based cementations material coupled with $\mathrm{Fe}_{2} \mathrm{O}_{3}$ catalyst for treatment of dye wastewater. Appl. Catal. B Environ., 138-139: 9-16.

Zhu, R. L., Zhu, L. Z., Zhu, J. X., Ge, F. and Wang, T. 2009. Sorption of naphthalene and phosphate to the CTMAB-Al13 intercalated bentonites. J. Hazard. Mater., 168: 1590-1594. 